\title{
GENITAL TRACT TUBERCULOSIS IN SUBFERTILE WOMEN
}

\author{
C. A. Morris, F. Norma Boxall and H. R. Cayton \\ Public Health Laboratory Service, and Maternal and Child Health Service, \\ Department of Public Health, Bristol
}

THIS paper describes the changing pattern of tuberculous genital tract infection over a 16-yr period in patients attending a subfertility clinic. The problem of diagnosis is discussed in relation to changes in the population at risk and increased demands on the clinical and pathological services available. The relative merits of the laboratory diagnostic methods are discussed.

\section{MATERIALS AND METHODS}

\section{The population}

Between the years 1953 and 1968, 3384 women have been investigated in a clinic for subfertility of primary or secondary type. The patients were referred by general practitioners, by family planning clinics, by hospital or marriage guidance consultants and sometimes by a previous patient. Each year from 10 to 20 per cent. of patients failed to complete the investigations, but of the remainder approximately 1 in 3 had a subsequent successful pregnancy.

A notable feature of this 16 -yr period has been the reduction in the average age of patients seeking advice: in 1953 less than 25 per cent. of patients were aged 25 or under, whereas by 1968 almost 50 per cent. were in this age-group. Over these years there has been an increasing proportion of patients attending primarily for help over marital difficulties. The proportion of immigrants has remained low, forming less than 5 per cent. of the new patients in 1968 .

\section{Diagnosis of tuberculosis of the genital tract}

The clinical history taken from each patient included enquiries into previous BCG vaccination. A record was made of any history of tuberculosis, of respiratory or other diseases and of close contact with a known case of tuberculosis.

In addition to a routine gynaecological examination and chest X-radiograph for all patients, tuberculin tests were performed on those women who had not had BCG vaccination. Unless an obvious cause of subfertility had been found on preliminary examination, endometrial biopsies were obtained from almost all patients completing their investigations during the early years. The number of patients investigated has been reduced during the past 4 yr by using the following protocol: patients who gave negative tuberculin tests were assumed to be free of infection and those who had had BCG vaccine were regarded as immune. Women who gave a positive tuberculin reaction in the absence of immunisation were considered to have been infected, and to require investigation before tuberculosis could be excluded as the cause of their subfertility. Endometrial samples were collected from this group of patients and culture for tubercle bacilli, histological examination and guinea-pig inoculation were carried out on them. When possible, endometrial biopsies were collected at an out-patient clinic without the use of anaesthesia. About 10 per cent. of patients were

Received 13 May 1969; accepted 8 July 1969.

J. MED. MICROBIOL.-VOL. 3 (1970) 
regarded as physically or psychologically unsuited for this operative procedure and were admitted to hospital for a cervical dilatation and diagnostic curettage.

If all three tests were negative, the patient was considered to have no pelvic tuberculosis, unless the physical examination had revealed a pelvic mass and there were good reasons for an exploratory laparotomy.

Preparation of endometrial tissue for animal inoculation. Endometrial samples, often single small fragments of tissue, were received in sterile screw-capped "Universal" containers; $3 \mathrm{ml}$ of sterile normal saline and 2 sterile steel half-inch "panel pins "were added to each bottle and the tissue was blended for 3-7 min. with a magnetic stirrer until a suspension was formed. This method is to be published in more detail by Mr R. S. Shannon. Each of

TABLE I

Diagnosis of genital tract tuberculosis in 37 subfertile women by means of endometrial samples and laparotomy

\begin{tabular}{|c|c|c|c|c|}
\hline \multirow{2}{*}{$\begin{array}{l}\text { Number of } \\
\text { patients }\end{array}$} & \multicolumn{3}{|c|}{ Result of } & \multirow{2}{*}{$\begin{array}{l}\text { Special pathological } \\
\text { features }\end{array}$} \\
\hline & $\begin{array}{l}\text { guinea-pig } \\
\text { inoculation }\end{array}$ & $\begin{array}{l}\text { histological } \\
\text { examination }\end{array}$ & $\begin{array}{l}\text { culture for } \\
\text { mycobacteria }\end{array}$ & \\
\hline 3 & + & + & + & Myco. tuberculosis \\
\hline 8 & + & + & - & Myco. tuberculosis \\
\hline 16 & + & - & - & Myco. tuberculosis \\
\hline 3 & + & - & + & Myco. tuberculosis \\
\hline $\begin{array}{l}1 \\
1\end{array}$ & 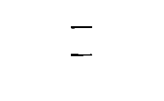 & + & $\bar{t}$ & $\begin{array}{l}\text { Single granuloma found } \\
\text { An " anonymous" } \\
\text { mycobacterium isolated }\end{array}$ \\
\hline 5 & - & - & - & $\begin{array}{l}\text { Tuberculous salpingitis } \\
\text { diagnosed at laparotomy }\end{array}$ \\
\hline
\end{tabular}

2 guinea-pigs was given an intramuscular inoculation of $1 \mathrm{ml}$ of the tissue suspension; one of the animals was killed and examined after $4 \mathrm{wk}$ and the other after $6 \mathrm{wk}$. Films and cultures were made from any suspicious lesions and the organism if present was identified as Mycobacterium tuberculosis by standard methods. Samples of uterine curettings that gave rise to obvious tuberculosis in guinea-pigs examined $6 \mathrm{wk}$ after inoculation had been positive within 4 wk in only two-thirds of the total positive cases.

Cultural methods. The endometrial samples were cultured on Löwenstein-Jensen medium. The preliminary treatment of the specimens after maceration and before inoculation of the medium has varied according to the hospital laboratory performing the examinations and has not always remained constant within the same laboratory. The predominant method has been digestion with 6 per cent. oxalic acid.

\section{RESULTS}

Forty-two patients had active tuberculosis; 4 of these were already under treatment for previously diagnosed infection before they attended this clinic. Table I defines the mode of pathological diagnosis, but excludes data from the 4 patients mentioned above and also from 2 patients whose endometrial biopsy 
material gave positive guinea-pig results, but for whom the data on culture and histology were not available. Five patients diagnosed at laparotomy were found to have tuberculous salpingitis without evidence of spread to the endometrium. Thirty of the remaining 32 patients gave positive guinea-pig inoculation results, which were confirmed by histological appearances in 11 patients

TABLE II

Tuberculosis of the genital tract in relation to past history in subfertile women

\begin{tabular}{|c|c|c|c|c|c|c|c|}
\hline \multirow{3}{*}{ Year } & \multirow{3}{*}{$\begin{array}{c}\text { Total } \\
\text { patients }\end{array}$} & \multirow{3}{*}{$\begin{array}{c}\text { Patients } \\
\text { with genital } \\
\text { tract } \\
\text { tuberculosis }\end{array}$} & \multicolumn{5}{|c|}{$\begin{array}{l}\text { Ratio of patients with genital tract tuberculosis } \\
\text { to those with or without past history of tuberculosis }\end{array}$} \\
\hline & & & \multicolumn{2}{|c|}{$\begin{array}{l}\text { History of } \\
\text { tuberculosis }\end{array}$} & \multicolumn{3}{|c|}{ No history of tuberculosis } \\
\hline & & & $\begin{array}{l}\text { before } \\
\text { puberty }\end{array}$ & $\begin{array}{c}\text { after } \\
\text { puberty }\end{array}$ & " $\begin{array}{c}\text { History of } \\
\text { pneumplicated }\end{array}, * *$ & $\begin{array}{l}\text { Contact } \\
\text { with case of } \\
\text { tuberculosis }\end{array}$ & $\begin{array}{l}\text { No contact } \\
\text { with case of } \\
\text { tuberculosis }\end{array}$ \\
\hline $\begin{array}{l}1953 \\
1954 \\
1955 \\
1956 \\
1957 \\
1958 \\
1959 \\
1960 \\
1961 \\
1962 \\
1963 \\
1964 \\
1965 \\
1966 \\
1967 \\
1968\end{array}$ & $\begin{array}{l}111 \\
156 \\
157 \\
181 \\
205 \\
180 \\
229 \\
212 \\
267 \\
211 \\
230 \\
247 \\
239 \\
238 \\
253 \\
268\end{array}$ & $\begin{array}{l}3 \\
7 \\
2 \\
4 \\
2 \\
5 \\
3 \\
4 \\
3 \\
5 \\
1 \\
0 \\
1 \\
1 \\
0 \\
1\end{array}$ & $\begin{array}{l}0 / 5 \\
0 / 1 \\
0 / 2 \\
0 / 3 \\
0 / 3 \\
1 / 4 \\
0 / 2 \\
0 / 5 \\
0 / 7 \\
0 / 3 \\
0 / 2 \\
0 / 2 \\
0 / 3 \\
0 / 5 \\
0 / 3 \\
0 / 1\end{array}$ & $\begin{array}{l}0 / 9 \\
4 / 8 \\
0 / 6 \\
2 / 14 \\
0 / 5 \\
1 / 11 \\
1 / 6 \\
3 / 9 \\
1 / 12 \\
1 / 13 \\
0 / 10 \\
0 / 6 \\
0 / 3 \\
0 / 3 \\
0 / 5 \\
0 / 2\end{array}$ & $\begin{array}{l}0 / 1 \\
1 / 4 \\
0 / 10 \\
1 / 4 \\
1 / 3 \\
1 / 4 \\
0 / 2 \\
0 / 3 \\
1 / 3 \\
0 / 2 \\
1 / 5 \\
0 / 3 \\
1 / 3 \\
0 / 1 \\
0 / 2 \\
0 / 2\end{array}$ & $\begin{array}{l}0 / 8 \\
1 / 10 \\
0 / 8 \\
0 / 9 \\
0 / 16 \\
1 / 12 \\
0 / 12 \\
0 / 19 \\
2 / 21 \\
0 / 18 \\
0 / 15 \\
0 / 25 \\
0 / 20 \\
0 / 27 \\
0 / 16 \\
0 / 35\end{array}$ & $\begin{array}{l}3 / 88 \\
1 / 133 \\
2 / 131 \\
1 / 151 \\
1 / 178 \\
1 / 149 \\
2 / 207 \\
1 / 176 \\
1 / 224 \\
2 / 175 \\
0 / 198 \\
0 / 211 \\
0 / 210 \\
1 / 202 \\
0 / 227 \\
1 / 228\end{array}$ \\
\hline $\begin{array}{l}\text { Total } \\
(16 \mathrm{yr})\end{array}$ & 3384 & 42 & $1 / 51$ & $13 / 122$ & $7 / 52$ & $4 / 271$ & $17 / 2888$ \\
\hline $\begin{array}{l}\text { Genital tract } \\
\text { tuberculosis } \\
\text { percentage of } \\
\text { patients } \\
\text { "at risk" }\end{array}$ & $1 \cdot 24$ & & 1.96 & 10.65 & $13 \cdot 46$ & 1.48 & 0.59 \\
\hline
\end{tabular}

* Pneumonia complicated by pleurisy, effusion or empyema.

and by cultures in 6 . A single granulomatous lesion was identified in biopsy material from one patient from whom both culture and guinea-pig inoculations were negative; no acid-fast bacilli were identified in this histological lesion, but the patient had had recent treatment for pulmonary tuberculosis. None of these tuberculous infections was identified by culture alone. An anonymous mycobacterium was cultured from two endometrial biopsies collected on separate occasions from one patient. 
The relation of these infections to a history of tuberculosis or to an episode of pneumonia complicated by pleurisy, effusion or empyema or contact with an open case is given in table II. The isolations are expressed as a ratio of the patients attending the clinic who gave such a history; this is a measure of those who may be regarded as being "at risk" of developing subsequent pelvic tuberculosis. In this table patients are classified as post-pubertal if aged $11 \mathrm{yr}$ or more at the time of their primary tuberculous infection. Women who gave a history of pneumonia without complications are not included, nor are those in whom on routine radiography a quiescent primary lung focus was found-both these occurred commonly and were unhelpful in indicating patients at particular risk of developing genital tract tuberculosis.

\section{Discussion}

Tuberculosis of the female genital tract is generally a local manifestation of general disease, and is usually secondary to infection of the lungs or pleurae by human strains of Myco. tuberculosis (Jedberg, 1950; Barns, 1955; Sutherland, 1958). The incidence of active tuberculosis amongst patients attending this clinic has fallen from 2.7 per cent. in 1953 to 0.37 per cent. in 1968 . The clinical histories of patients may help: half of those who have tuberculosis as the cause of their subfertility give a history of past tuberculous infection or of "complicated pneumonia". Active tuberculosis was found in 10.6 per cent. of women with a history of tuberculosis in early adult life and in 13.5 per cent. of those who had had "complicated pneumonia"; this is in marked contrast to the incidence of only 0.6 per cent. pelvic tuberculosis among patients with no such past history. A history of tuberculosis in early childhood or of a home contact with tuberculosis was of less significance. Seventeen of the 42 patients with active tuberculosis had no relevant past or family histories. Ten of the 13 patients with active tuberculosis and a past history of primary infection in early adult life had developed a primary complex when aged 15 yr or over; the remaining three were first infected nearer puberty when the fallopian tubes are said to be particularly vulnerable to attack (Jedberg).

The Heaf tuberculin test has been a useful means of detecting patients with past infection. As the number of patients immunised with BCG is increasing this method is now less valuable.

In this study, patients who presented with infertility and were found to have pelvic tuberculosis had in the main few other symptoms or signs. These women, with a single exception, had little or no disturbance of the menstrual function. Several patients complained of dyspareunia. Rhodes (1960) has pointed out that patients who have infertility as their presenting symptom rarely have any physical signs in the pelvis, a feature confirmed by this series.

Five patients had tuberculous salpingitis without apparent involvement of the endometrium. Rhodes states that after haematogenous spread of tubercle bacilli from the primary site to the fallopian tubes there is direct spread from the tubes to the uterus in 90 per cent. of patients. Haines (1958) found that tuberculosis affects the fallopian tubes twice as often as the endometrium. 
In the pathological diagnosis of tuberculous endometritis guinea-pig inoculation was notably superior to histology and cultural methods. Rhodes recommended full curettage. Certainly the small amount of tissue obtained by biopsy, even when collected at the proliferative phase of the menstrual cycle, is less satisfactory for laboratory examination than curettings. Increased demands on gynaecological surgical skills and operating theatres have so lengthened the waiting period for these relatively less urgent diagnostic hospital admissions, that the simpler out-patient biopsy procedure has become a necessary compromise. In this study, 16 of 31 patients with tuberculous endometritis would not have been detected if reliance had been placed on culture or histological appearances only. On the basis of these observations we believe guinea-pig inoculation to be essential when endometrial biopsy material is examined for the presence of tubercle bacilli, but we agree with Vollum (1954) that no single method should be relied on for the diagnosis of tuberculous endometritis.

The importance of determining the identity of any mycobacterium isolated is shown by this study. Acid and alcohol-fast bacilli were seen in the direct smears of two endometrial biopsy samples collected from one patient on two occasions; from both samples a mycobacterium was cultured, but neither strain was virulent for guinea-pigs. No granulomatous lesion was found by histological examination of the biopsy material. The patient subsequently had two full-term uneventful pregnancies. The identity of this anonymous mycobacterium was unfortunately not established. Atypical mycobacteria are rarely found as presumptive pathogens in the genital tract. Engbaek et al. (1967) isolated Mycobacterium xenopei from an abscess of the epididymis. $\mathrm{Mr}$ C. H. Collins (personal communication) has identified the same species and also Mycobacterium scrofulaceum among strains submitted to him as isolates from endometrial curettings, though the probability that these were contaminants is high. One of us (C. A. M.) has been unable to find mycobacteria during a study of vaginal and urethral swabs from seventy " normal " women attending for cervical cytology examinations. Anonymous mycobacteria appear to be uncommon in the female genital tract and their pathogenic role is undetermined.

Tuberculosis as a cause of subfertility has declined since the introduction of treatment with streptomycin and BCG vaccination, but foci of infection remain in the community and may be unsuspected until necropsy (Fullerton, 1969). Additional sources of bacilli are introduced as a result of international travel (Ministry of Health, 1968). Examination for tuberculosis of the genital tract should therefore be thorough and conscientious. Its unrecognised presence may also endanger children.

\section{SUMMARY}

Between 1953 and 1968, 42 of 3384 women attending a subfertility clinic were found to have genital tract tuberculosis.

The examination of endometrial biopsies by guinea-pig inoculation was the most reliable method of detecting tuberculous endometritis, and was more 
sensitive than histological and cultural methods. Sixteen of 31 patients would not have been identified without the use of animal inoculation.

The tuberculin test was a useful preliminary for those patients who required a diagnostic endometrial examination.

Patients with a history of primary tuberculosis in early adult life or of pneumonia complicated by pleurisy, effusion or empyema were significantly more likely to have genital tract tuberculosis than were women without such a history. The past and family histories, however, gave no clue to the diagnosis in nearly half of the patients with pelvic tuberculosis.

\section{REFERENCES}

BARNS, T. . . . . . . . 1955. J. Obstet. Gynaec. Br. Emp., 62, 162.

EngBaek, H. C., Vergmann, B., Baess, I., 1967. Acta path. microbiol. scand., 69, 577. AND WILL, D. W.

Fullerton, JANE M. . . . . $\quad$. 1969. Br. Med.J., 1, 715.

HAINES, M. . . . . . . 1958. Amer. J. Obstet. Gynec., 75, 472.

JeDBerG, H. . . . . . . . 1950. Acta obstet. gynec. scand., 31, Suppl. 1.

Ministry of Health . . . . 1968. On the State of the Public Health. Annual Report of the Chief Medical Officer for the year 1967, London, H.M.S.O., p. 79.

Rhodes, P. . . . . . . . . 1960. Practitioner, 185, 290.

Sutherland, A. M. . . . 1958. J. Obstet. Gynaec. Br. Emp., 65, 450.

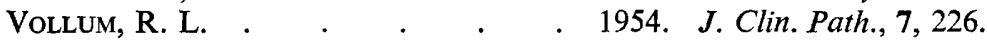

